\title{
Conducting polymer coatings in electrochemical technology Part 2 - Application areas
}

\author{
C. Ponce de León ${ }^{1}$, S. A. Campbell ${ }^{2}$, J. R. Smith ${ }^{2}$ and F. C. Walsh*1
}

\begin{abstract}
Conducting polymers can combine the electronic characteristics of metals with the engineering properties of polymers. Polypyrrole (PPy), polythiophene (PTh) and polyaniline (PAni) are common examples of conducting polymers which can be electrodeposited from their respective heterocyclic monomers. The applications of these and other electrodeposited polymer materials are considered in this review. Application areas include electronic and optical materials, sensors, bioimplants, actuators and corrosion protection together with electrical energy storage. Specialised coatings include composite and multilayer deposits consisting of a conducting polymer coating and a second phase of metal or ceramic.
\end{abstract}

Keywords: Conducting polymers, Composite coatings, Electrochemical deposition, Layered coatings, Organic coatings, Polyaniline, Polypyrrole, Polythiophene, Thin films

\section{Introduction}

A previous review ${ }^{1}$ has profiled typical conductive polymers together with their synthesis and fundamental properties. In the last 40 years, considerable knowledge of such materials has been gained and this is reflected in a number of texts and early reviews. ${ }^{2-6}$ Conductive polymers are becoming increasingly adaptable to applications which previously belonged to metals and their conductive compounds. A prime advantage in using polymers instead of metals is that a significant weight saving can often be obtained. This has led to polymers being increasingly used as construction materials, ${ }^{7}$ rather than just as small components. Other applications of these materials include current carriers in electronic components $^{8-11}$ where weight saving is again advantageous. Electroactive polymers are also, in general, less toxic and potentially less damaging to the environment than many commonly used metals. Some of the many applications of electroactive polymers are illustrated in Table 1 and are considered in more detail in this paper. The range and tunability of conducting polymers' properties (Table 2), the synthesis of new materials and process experience continue to facilitate diverse applications.

\section{Electronic and optical materials}

\section{Electrochromic cells}

An important area of current research is in the use of electroactive polymers in flat screen displays for

${ }^{1}$ Electrochemical Engineering Laboratory, Materials Engineering Research Group, School of Engineering Sciences, University of Southampton, Highfield, Southampton SO17 1BJ, UK

${ }^{2}$ Applied Electrochemistry Group, School of Pharmacy and Biomedical Sciences, University of Portsmouth, St Michael's Building, White Swan Road, Portsmouth PO1 2DT, UK

*Corresponding author, email f.c.walsh@soton.ac.uk computers, personal digital assistants, new screens and mobile phones. Electrochromic materials can be made to change colour, texture or contrast under the influence of an electrical current and can be produced as thin, regular films where the required properties such as the intensity and wavelength of the light they can transmit, can be precisely controlled. ${ }^{22}$ The use of solid polymer electrolytes, which are more convenient to handle and contain less hazardous chemicals than their liquid electrolyte predecessors, has led to the development of new devices such as photoelectrochemical cells and light emitting diodes ${ }^{23,24}$ as examples of the wide range of optical applications offered by electroactive polymers.

Hwang et al. studied the optical properties of poly(3,4-ethylenedioxythiophene) (PEDOT), poly(3,4propylenedioxythiophene) and poly(3,4-2,2-dimethylpropylenedioxy) thiophene in their neutral, light and highly doped states. The doping state is the base of the strong visible electrochromism observed in these polymers as the $\pi-\pi^{*}$ transition disappears in the highly doped state. The polymers were deposited as thin films on electronically conducting indium tin oxide (ITO) substrates. A schematic diagram of the conductive polymer layer on an ITO layer on a thick glass substrate is shown in Fig. 1. The incident light is reflected on the polymer from the ITO layer and from the glass substrate. The absorption from each layer contributes to the reflectance and transmittance spectra. ${ }^{25}$

Interesting electrochromic properties such as a dark blue optical transparency in the neutral state and sky blue transmission when doped can be observed in PEDOT which is a stable and highly conductive polymer. The polymer can be switched rapidly between the doped and neutral states with a contrast ratio of $76 \%$. The low molecular weight counterion poly(styrene sulphonate) (PSS) dopant, produces a water soluble nearly transparent film and improves the electrochemical, optical, 


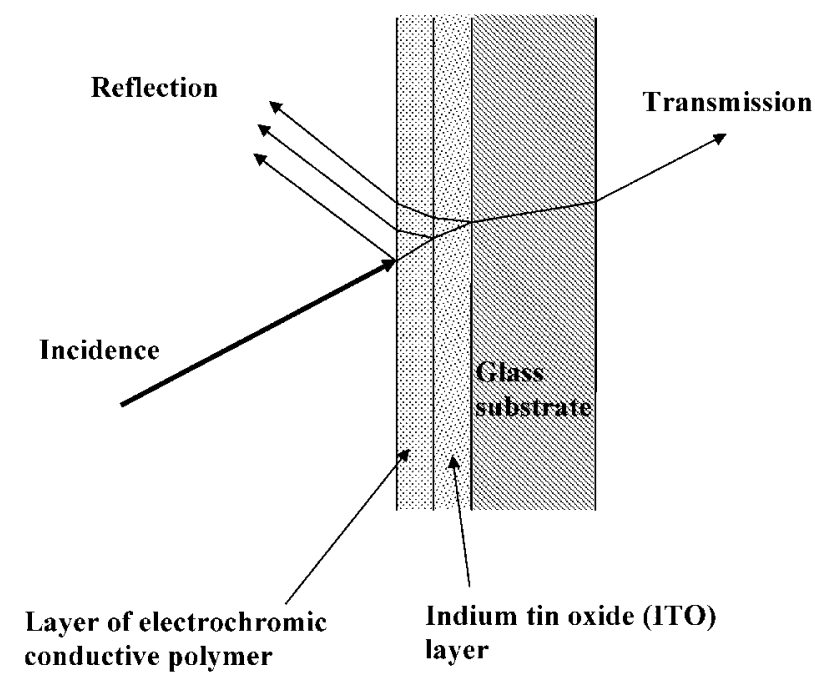

1 Conductive polymer layer on indium doped tin oxide (ITO) coated glass substrate

mechanical and transport properties of the free standing films. Cation exchange properties have been observed when PEDOT is doped with metal complexes such as $\mathrm{Ru}\left(\mathrm{NH}_{3}\right)_{6} \mathrm{Cl}_{3}$. Sonmez et al. ${ }^{26}$ studied the properties of electrochemically prepared PEDOT with a two million relative molar mass dopant poly(2-acrylamido-2-methyl1-propane sulphonate) on various substrates. The free standing films showed an electrical conductivity of $80 \mathrm{~S} \mathrm{~cm}^{-1}$, despite the high relative molar mass of the polyelectrolyte dopant. Conductivities of $230 \mathrm{~S} \mathrm{~cm}^{-1}$ have been observed when PEDOT is doped with small anions such as $\mathrm{PF}_{6}{ }^{-} \cdot{ }^{27}$ Poly(3,4-ethylenedioxythiophene) (PEDOT) can be used as polymer light emitting diodes when combined with an ITO substrate and an organic light emitter. ${ }^{18}$

Yashima et al. ${ }^{28}$ found that a honeycomb like structure of poly(isothianaphthene) with morphological units having typical dimensions of $20 \times 10^{-8} \mathrm{~cm}$ plays a critical role in the determination of electrochromic characteristics. Such morphology is considered to restrict the diffusion of the dopant in the polymer ion, resulting in switching times of a few hundreds of milliseconds.

\section{Electromagnetic shielding}

The safe and secure operation of electronic equipment increasingly requires minimal transfer of electromagnetic

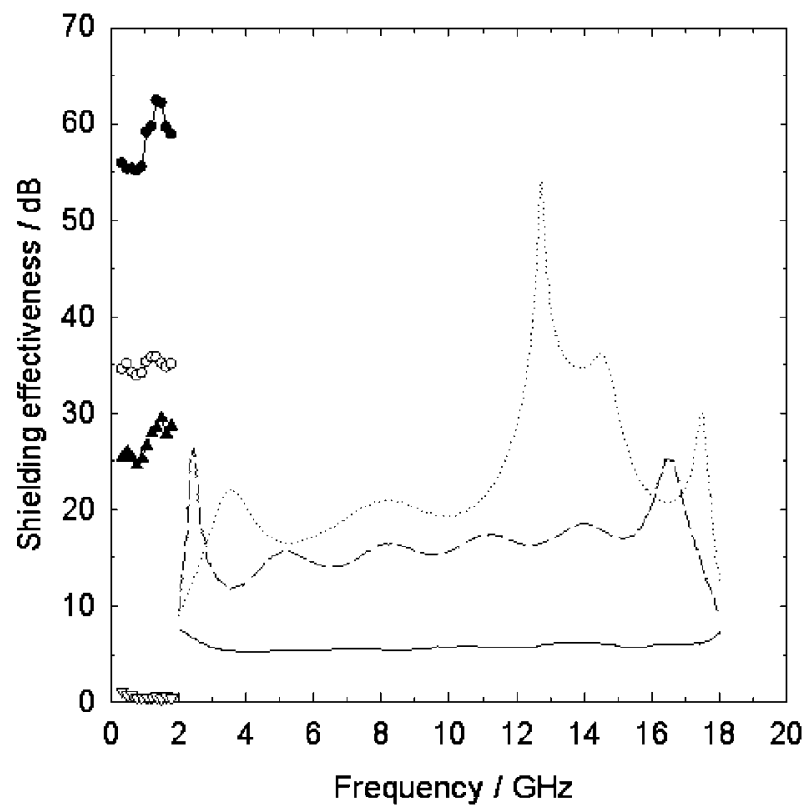

2 Shielding effectiveness of different polymeric materials and composites: number of layers of $0.1 \mathrm{~mm}$ MWCNT/ PMMA coated PET film: solid line (-): one layer, dashed line $(---)$ : five layers, dotted line (o.o.): nine layers; ${ }^{34}$ 50 wt-\% conductive carbon nanomaterial filled LCPs and MF nanocomposites: $\Delta$ : amorphous carbon, $\bullet$ : CNTs desunnanol/LPC, $\bigcirc:$ CNTs KUAS/MF, $\nabla:$ raw MF $^{35}$

radiation to (and from) other electrical and electronic equipment. For portable equipment, low cost, lightweight and strong shielding protection are often required. Several conducting polymers have been shown to be efficient in various electromagnetic interference (EMI) shielding applications, using both far field and near field shielding measurement techniques. ${ }^{29,30}$ Composite coatings of polypyrrole (PPy) and polyaniline (PAni) with metal fibres, metal particulates $(\mathrm{Ag} / \mathrm{Pd})$, graphite or carbon black fillers have been used in EMI shielding. ${ }^{31}$ The shielding effectiveness (SE) of the polymer barrier depends on the ability of the conducting polymer to reflect, transmit or absorb radiation in function of its permeability, conductivity and thickness.

Chemical synthesis of aqueous PPy containing ptoluene-2-sulphonic acid (PTSA) as dopant and $\mathrm{FeCl}_{3}$ as oxidant can provide uniform coatings on textile fabrics.

Table 1 Applications of conductive polymer deposits

\begin{tabular}{|c|c|c|c|c|}
\hline Application area & Specific application & Polymer & Dopant & $\begin{array}{l}\text { Year } \\
\text { (reference no.) }\end{array}$ \\
\hline $\begin{array}{l}\text { Scaffolds for tissue } \\
\text { engineering }\end{array}$ & Neural tissue growth in vivo & Poly(pyrrole) (PPy) & $\begin{array}{l}\text { Poly(styrene sulphonate) } \\
\text { (PSS) and sodium } \\
\text { dodecylbenzene } \\
\text { sulphonate (NaDBS) }\end{array}$ & $2005(12)$ \\
\hline $\begin{array}{l}\text { Biomimetic sensors, } \\
\text { robotic actuators } \\
\text { and artificial muscles }\end{array}$ & Actuator & $\begin{array}{l}\text { Perfluorinated alkenes with } \\
\text { Nafion }\end{array}$ & $\mathrm{Ag}$ and $\mathrm{Pd}$ & $2002(13)$ \\
\hline Corrosion protection & $\begin{array}{l}\text { Anticorrosive additive in } \\
\text { marine paints }\end{array}$ & $\begin{array}{l}\text { Polythiophene (PTh), } \\
\text { polyaniline (PAni) and PPy }\end{array}$ & $\mathrm{LiClO}_{4}$ & 2007 (14) \\
\hline $\begin{array}{l}\text { Scaffolds orthopaedic } \\
\text { applications }\end{array}$ & $\begin{array}{l}\text { Scaffolds exposed to the } \\
\text { mouse stromal cells }\end{array}$ & $\begin{array}{l}\text { Poly }(\varepsilon \text {-caprolactone) } \\
\text { (PCL) and PAni }\end{array}$ & $\begin{array}{l}\text { Aqueous protonic or } \\
\text { functionalised acid such as } \\
\text { camphorsulfonic acid (HCSA) }\end{array}$ & 2007 (15) \\
\hline Corrosion protection & $\begin{array}{l}\text { Steel protection in } \mathrm{NaCl}(3 \%) \\
\text { solution over } 35 \text { days }\end{array}$ & PAni-TiO 2 composite (PCT) & $\mathrm{TiO}_{2}$ & 2007 (16) \\
\hline Energy conversion & Rechargeable battery & PAni-TiO 2 composite (PCT) & $\mathrm{TiO}_{2}$ & $2003(17)$ \\
\hline
\end{tabular}


The dielectric properties of the coating show that the electromagnetic radiation permittivity decreases at higher frequencies in the range of $1-18 \mathrm{MHz}$. The SE of the coated textile increased at long polymerisation times, but was not influenced by the morphology of the coating. A high SE, up to $86 \%$, was observed at high concentrations of the dopant ion due to the increasing conductivity in the chemical structure of the polymer. ${ }^{32}$

Kumar et al. studied the SE of free standing cast PAni films of various thicknesses using PTSA and camphor10 -sulphonic acid as a primary dopant with 4-chloro3-methylphenol as a secondary dopant, the later promoting crystallinity of the polymer. ${ }^{33}$

Multiwall carbon nanotubes/poly(methyl methacrylate) (MWCNT/PMMA) composites have been prepared by in situ and ex situ methods. Scanning electron microscopy (SEM) images revealed high SE values. Additionally, composites prepared by stacking 10 layers of $0 \cdot 1 \mathrm{~mm}$ MWCNT/PMMA showed a higher SE than that prepared from a single $1.0 \mathrm{~mm}$ thick piece of bulk MWCNT/PMMA. ${ }^{34}$ Figure 2 shows a comparison of the SE of different conductive polymeric materials and composites as a function of the electromagnetic interference frequency. Multiwall carbon nanotubes and polymer methyl methacrylate (MWCNT/PMMA) composites were prepared in situ to coat a poly(ethylene terephthalate) (PET) film with layers of $0.1 \mathrm{~mm}$ MWCNT/PMMA. ${ }^{34}$ Figure 2 shows the SE factor for a $0.1 \mathrm{~mm}$ film of poly(ethylene) coated with one, five and nine layers of $0.1 \mathrm{~mm} 4.76 \mathrm{wt}-\% \mathrm{MWCNT} / \mathrm{PMMA}$; the SE increased with the number of layers. The figure also shows the SE factor for $50 \mathrm{wt}-\%$ conductive carbon nanomaterials filled liquid crystal polymers (LCPs) and melamine formaldehyde (MF) nanocomposites: amorphous carbon, purified carbon nanotubes made by chemical vapour deposition (CNTs desunnanol/ LPC), non-purified carbon nanotubes and melamine formaldehydes (CNTs KUAS/MF) and raw MF. ${ }^{35}$ The highest SE of these materials was $\sim 60 \mathrm{~dB}$ for CNTs produced by the chemical vapour deposition method and liquid polymer crystal (CNTs desunnanol/LPC) appropriate for industrial applications. The range of frequency reported was, however, rather short.

\section{Sensors and actuators}

\section{Sensors}

The use of conducting polymers in sensors components is a popular research area as such devices can show much higher sensitivities than some conventional systems. Electroactive polymers can change their properties when varying ions and solvents are used in the polymerisation process and this effect can be exploited in ion selective sensors. ${ }^{36}$ Development of conductive polymer materials has extended the range of sensor applications to nitrogen oxides detectors, ${ }^{37}$ a range of organic vapour and gas sensors ${ }^{38-41}$ and biosensors. ${ }^{42,43}$ PPy can often be used to produce reliable and accurate sensors, due to its high environmental stability; it can also be made sensitive to a wide variety of chemical species.

Polymeric composite sensors shrink or swell in response to different vapour environments causing the resistivity of composites consisted of carbon black (CB) arrays and non-conductive polymers such as: poly(4vinylphenol), poly(vinyl acetate), polysulphone and others. Carbon black (CB) is the conductive phase and the composite can distinguish among toluene, methanol, 2-propanol, hexane, ethyl acetate, ethanol, chloroform, benzene and acetone in the gas phase, although selectivity was relatively poor. ${ }^{44} \mathrm{PPy}$, rather than $\mathrm{CB}$, can be used as the conducting phase. ${ }^{45}$ To improve selectivity, Zeng et al. used the hydrophobic characteristics of $\mathrm{CB}$ filled waterborne $\beta$-cyclodextrin-block poly(diethylene glycol hexandioic ester) (waterborne $\beta$-CD-block-PDEA) copolymer composite to specifically absorb organic solvent molecules in the gas phase. ${ }^{46}$ In an earlier work, the authors observed changes in conductivity of the composites which demonstrated the sensitivity of these materials to organic solvent vapours. Using CDs, the authors found that $\mathrm{CB}$ filled waterborne $\beta$-CD-block-PDEA copolymer composites were sensitive to low permeability organic vapours, although no response was observed with high permittivity vapours. The response of the low permeability vapours depended on the molecular size of the vapours.

Redox and conductive properties were observed in a water soluble, biodegradable copolymer formed between PAni and gum arabic (GA) in acid using peroxydisulphate as initiator and oxidant. The water solubility of the copolymer increased with the percentage of GA and the redox properties of the copolymer were similar to those observed in pure PAni films. The optimum grafting conditions to form GA-graft-PAni (GA-gPAni) were $\left(\mathrm{NH}_{4}\right)_{2} \mathrm{~S}_{2} \mathrm{O}_{8} \quad\left(0.5 \mathrm{~mol} \mathrm{dm}^{-3}\right)$, aniline $\left(0.2 \mathrm{~mol} \mathrm{dm}^{-3}\right), \mathrm{HCl}\left(1.25 \mathrm{~mol} \mathrm{dm}^{-3}\right)$ and GA $\left(80 \mathrm{~g} \mathrm{dm}^{-3}\right)$ at $40^{\circ} \mathrm{C}$. The GA-g-PAni exhibited an electrical conductivity of $5 \cdot 18 \times 10^{-2} \mathrm{~S} \mathrm{~cm}^{-1}$ and was claimed to be biodegradable within $3000 \mathrm{~h}$ at $\mathrm{pH} 1 .{ }^{19}$

Table 2 Important properties of conductive polymers

\begin{tabular}{|c|c|c|c|}
\hline Polymer & Property & Controlled by & $\begin{array}{l}\text { Year } \\
\text { (reference no.) }\end{array}$ \\
\hline $\begin{array}{l}\text { Poly(3,4-ethylenedioxy-thiophene)/poly(styrene sulphonate) } \\
\text { (PEDOT/PSS) }\end{array}$ & Electrical conductivity & $\begin{array}{l}\text { Solvent matrix and laser } \\
\text { irradiation wavelength }\end{array}$ & $2007(18)$ \\
\hline poly( $\varepsilon$-caprolactone) (PCL) and poly(aniline) (PAni) & $\begin{array}{l}\text { Synthetic scaffolds for } \\
\text { orthopaedic applications }\end{array}$ & $\begin{array}{l}\text { Electrical current } \\
\text { accelerates calcification }\end{array}$ & $2007(15)$ \\
\hline $\begin{array}{l}\text { Gum arabic(GA)-graft-PAni. Biodegradable grafted } \\
\text { biopolymers from renewable sources for environmentally } \\
\text { friendly devices }\end{array}$ & Electrical conductivity & $\begin{array}{l}\text { Increases from } 4.73 \times 10^{-6} \text { to } \\
5 \cdot 18 \times 10^{-2} \mathrm{~S} \mathrm{~cm}^{-1} \text { due to } \\
\text { the grafting of PAni } \\
\text { on GA }\end{array}$ & $2007(19)$ \\
\hline \multirow[t]{4}{*}{ PAni } & Electrical conductivity & $0.0125 \mathrm{~S} \mathrm{~cm}^{-1}$ & 2007 (16) \\
\hline & & $2.4 \times 10^{-3} \mathrm{~S} \mathrm{~cm}^{-1}$ & $2005(20)$ \\
\hline & & $0.04 \mathrm{~S} \mathrm{~cm}^{-1}$ & $2003(17)$ \\
\hline & & $0 \cdot 16-7 \cdot 0 \mathrm{~S} \mathrm{~cm}^{--1}$ & $2005(21)$ \\
\hline
\end{tabular}




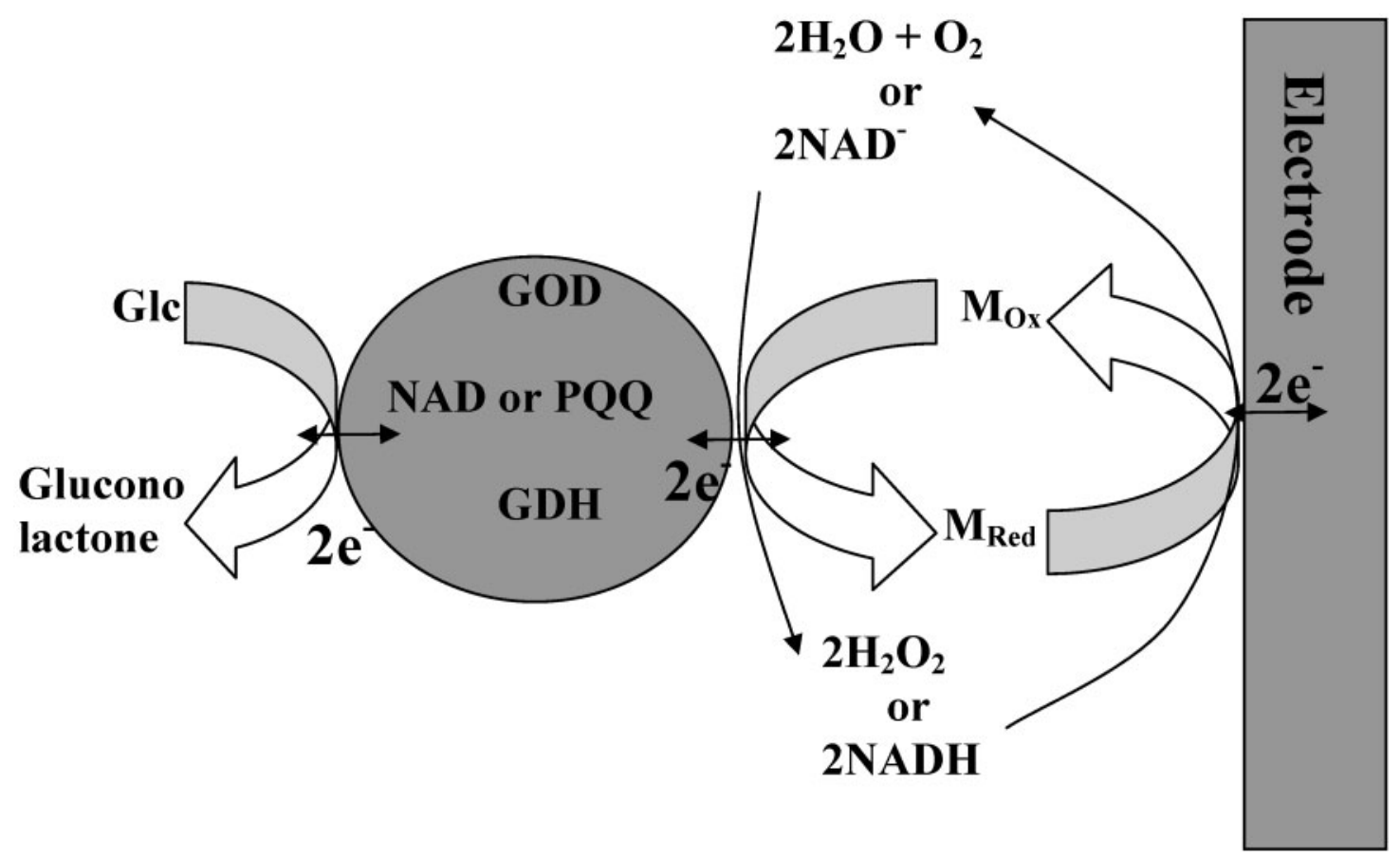

3 Electrochemical biosensors based on glucose oxidase (GOD), where $M_{\mathrm{ox}}$ and $M_{\text {red }}$ indicate the oxidised and reduced forms of redox mediators

Biosensors consist of an immobilised biocatalyst, normally redox enzymes, reactive to a particular analyte, into a signal transducer. The catalytic reaction between analyte and catalyst can involve an electron transfer easily detected if an efficient electron transfer route exists. Glucose oxidase enzymes have been successfully used with PPy and PAni for glucose detection, although other coenzymes, such as flavin adenine dinucleotide (FAD), nicotinamide adenine dinucleotide $\left(\mathrm{NAD}^{+}\right)$and pyrroloquinoline quinone (PQQ), have been used as catalytic biosensors. The permeability of electrochemically formed conductive polymers, used to support the enzymes, allows access of the analytes to the catalytic sites of the enzyme. The activity of the enzyme embedded into the polymer matrix can be monitored by the response of the products to the applied current or potential. Figure 3 shows the principle of the electrochemical biosensors based on glucose oxidase where $M_{\text {ox }}$ and $M_{\text {red }}$ indicate the oxidised and reduced forms of the redox mediators. If FAD dependent oxidases are mediators, the production of $\mathrm{H}_{2} \mathrm{O}_{2}$ only occurs at very positive high potentials. The figure also shows the generalised scheme for biosensors based on $\mathrm{NAD}^{+}$ dependent glucose dehydrogenase and PQQ dependent glucose dehydrogenase. PQQ dependent enzymes are more reliable; unlike the NAD, PQQ enzymes are oxygen independent and can attach to the PPy, retaining their activity and able to transfer the electrons directly to the conducting surfaces of PPy. ${ }^{47}$

\section{Actuators}

Some conductive polymers change volume depending on the extent of oxidation, or due to an externally applied potential. The movement of dopant species into the film under these circumstances causes the film to swell, while on electroreduction, the movement of dopant out of the film allows contraction. This has led to the development of actuators which convert electrical energy into mechanical work. Such electroactive polymer actuators have been extensively studied ${ }^{48,49}$ and early 'selfcontained' actuators were reported. ${ }^{50}$ Several groups have investigated this property further. The emerging application of these devices is important for biomedical applications, such as artificial muscles in replacement limbs and cochlear transplants. ${ }^{51-53}$

Ionic polymer conductor composites are manufactured using perfluorinated alkenes containing fixed covalent ionic groups, such as sulphonate or carboxylate terminal groups for cationic ion interchange or ammonium groups for anionic interchange; polymers based on styrene divinylbenzene are also used. The preparation includes the metallisation of the inner surface of the conductive polymer with $\mathrm{Pt}$, although other conductive media, such as $\mathrm{Pd}, \mathrm{Ag}, \mathrm{Au}$, carbon, graphite or carbon nanotubes, can be used. The reduction of the metal ions on the conductive polymer can be carried out with borohydride and additives are used to improve dispersion of the metal. The morphology of the metal on the surface and inside the membrane depends on the preparation method, but in the case of $\mathrm{Pt}$, the metal is highly dispersed on the surface and dendritic and fractal growing occurs. The operation of the polymer as an actuator is affected by the water and hydrated ion transport within the molecular structure; water leakage from the surface of the metallised polymer should be eliminated because it reduces the efficiency of operation. When an electrical field is applied between the electrodes on the side of an ion conductive polymer strip, the cations drift carrying water molecules that accumulate near the cathode creating a local pressure deforming the material, as shown in Fig. 4. $^{54}$

\section{Corrosion protection}

Electroactive polymers have been suggested as viable alternatives to chromate conversion coatings ${ }^{55}$ and as 


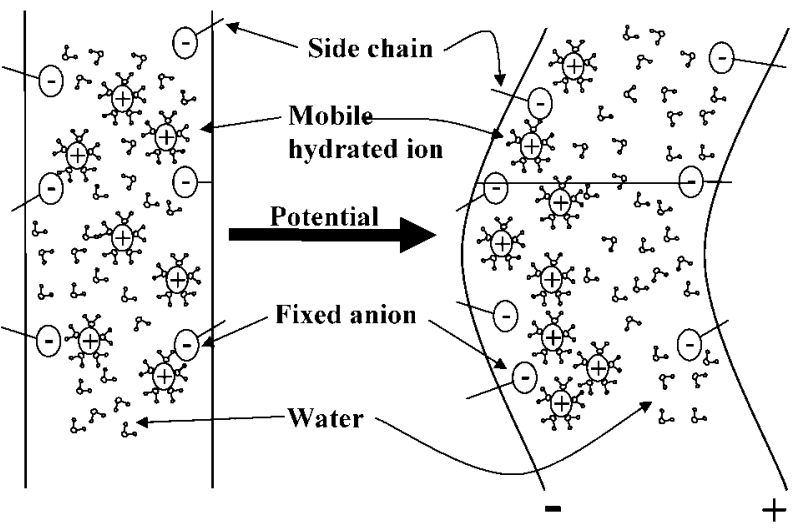

4 Electrophoretic migration of counterions inside ion polymeric metal composite chemical structure

coatings for corrosion protection. ${ }^{56}$ There have been numerous reports of the passivating effect of electroactive polymers on steels and $\mathrm{Al}$ in various environments. ${ }^{57}$ It has also been established that electroactive polymers, such as PAni and PPy, can provide useful levels of corrosion protection to mild steel in certain types of corrosion environments. ${ }^{58}$ In acidic saline solutions, PAni has been found to lower the corrosion rate of mild steel by a factor of 10 , compared to a halving of the corrosion rate with PPy. Poly(3methylthiophene) films have also been reported to passivate titanium, ${ }^{59}$ where, through galvanic coupling, the conductive film could maintain the substrate at a potential which conveyed passivity to the metal. The same polymer has also been investigated with stainless steel. PAni has been deposited onto aluminium alloys which were subsequently immersed in dilute Harrison solution $\left[0 \cdot 35 \%\left(\mathrm{NH}_{4}\right)_{2} \mathrm{SO}_{4}\right.$ and $0 \cdot 05 \% \mathrm{NaCl}$ in water] and investigated by impedance spectroscopy, Tafel analyses and open circuit potential measurements. PAni was found to decrease the corrosion and passivation currents, and impedance spectroscopy indicated that PAni promoted the growth of an insulating oxide film. For iron, drop cast PAni has been found to raise the corrosion potential of the metal to more noble values and significantly decrease the corrosion current when exposed to tap water, $\mathrm{HCl}\left(0 \cdot 1 \mathrm{~mol} \mathrm{dm}^{-3}\right)$ and $\mathrm{NaCl}(3.5 \%)$ environments. In the case of steel, electroactive polymers are thought to stabilise the potential in a passive region and in doing so, maintain a protective oxide layer on the metal surface. Oxygen reduction occurring on the polymer film replenishes the charge on the polymer, which is consumed by dissolution of the metal and stabilises the potential of the metal in that region. ${ }^{60}$ The mechanisms involved in the corrosion protection by electroactive polymers are still the subject of many researches and discussions. ${ }^{61-66}$

The corrosion protection efficiency of mild steel with a copolymer formed with pyrrole and 2-amino-4-phenylthiazole was $88 \%$ when the film was deposited during 10 min using a $0.05 \mathrm{~mol} \mathrm{dm}^{-3}$ monomer concentration. The kinetics of the electrochemical copolymerisation was studied in a mixture of $\mathrm{DMF} / \mathrm{H}_{2} \mathrm{O}(30: 70, \mathrm{v} / \mathrm{v})$ in an acidic aqueous $\mathrm{HCl}$ solution, with $0.05 \mathrm{~mol} \mathrm{dm}^{-3}$ of each monomer, using microgravimetric and electrochemical techniques, and corrosion test was carried out in $\mathrm{Na}_{2} \mathrm{SO}_{4}\left(0 \cdot 1 \mathrm{~mol} \mathrm{dm}{ }^{-3}\right){ }^{67}$

\section{Energy conversion: battery technology}

Batteries were one of the first applications suggested for the utilisation of electroactive polymers ${ }^{68-70}$ particularly as polymers with conjugated backbones have been found to have low ionisation energies ${ }^{71}$ and high electron affinities. ${ }^{72}$ The reversible redox chemistry of these polymers indicates that these materials may be used as thin flexible and robust electrodes in rechargeable storage batteries. ${ }^{73-76}$ An advantage of using electroactive polymers rather than metals is that the charging and discharging reactions (redox doping and undoping) create charged carriers along the conjugated backbones and there is no deposition or dissolution of the electrode material. Metal electrodes, however, can have morphological features at the electrode surface which can separate and break off, due to the repeated dissolution and deposition reactions.

Kim et al. evaluated the effect of cathode thickness of cast materials in an organic radical polymer battery. These environmentally friendly and high rate capable batteries contain at least one organic radical polymer as active material and are promising if specialised energy sources. The cathode consisted on $40 \%$ of the radical polymer poly (2,2,6,6-tetramethylpiperidinyloxy4-yl methacrylate) (PTMA) as active material and lithium. The casting film thickness was in the order of manometers over a conductive carbon. Cells with thin cathodes performed well delivering full discharge at high current densities in repeated cycles, while thicker cathodes exhibited resistance between the interface of the electrode and the electrolyte. ${ }^{77}$

The electrochemical and physicochemical properties of PAni prepared by oxidative polymerisation and doped with $\mathrm{TiO}_{2}$, were determined to use it as cathode for a rechargeable battery. The anode was zinc and the electrolyte was a solid polymer carboxy methyl cellulose and poly(vinyl sulphate). The electrodes were separated by a membrane fabricated with carboxy methyl cellulose. Batteries using PAni cathode only and $\mathrm{PAni} / \mathrm{TiO}_{2}$ cathodes showed an open circuit voltage of $1.4 \mathrm{~V}$. The $\mathrm{PAni} / \mathrm{TiO}_{2}$ cathode allowed for 50 rechargeable cycles while the PAni cathode battery allowed 30 cycles. Both batteries provided $350 \mathrm{~h} \mathrm{~kg}^{-1}$ power density at $70 \%$ power efficiency. ${ }^{17}$ Figure 5 shows a comparison between batteries operating with $\mathrm{PAni} / \mathrm{TiO}_{2}$ composite as a cathode assembled in zinc container anode and $\mathrm{Li} /$ PTMA batteries operating with the radical polymer PTMA based cathodes of different thicknesses. ${ }^{77}$ The curves show the discharge capacity as a function of cycles and it can be seen that the discharge capacity of the battery with $\mathrm{PAni} / \mathrm{TiO}_{2}$ cathode is large, whereas in the Li/PTMA batteries, the thinnest PTMA cathode presents the highest discharge capacity.

\section{Biomaterials}

The biocompatibility of PPy combined with its high conductivity and potentially large surface areas has been used for tissue regeneration, neural electrodes and nerve growth. The incorporation of biological dopants or bioactive materials in the structure or on the surface of PPy can modify its physicochemical properties with potential uses for nerve regeneration and neural electrodes. Gomez et al. studied the effect of the electrical stimulation on PPy with an immobilised nerve 


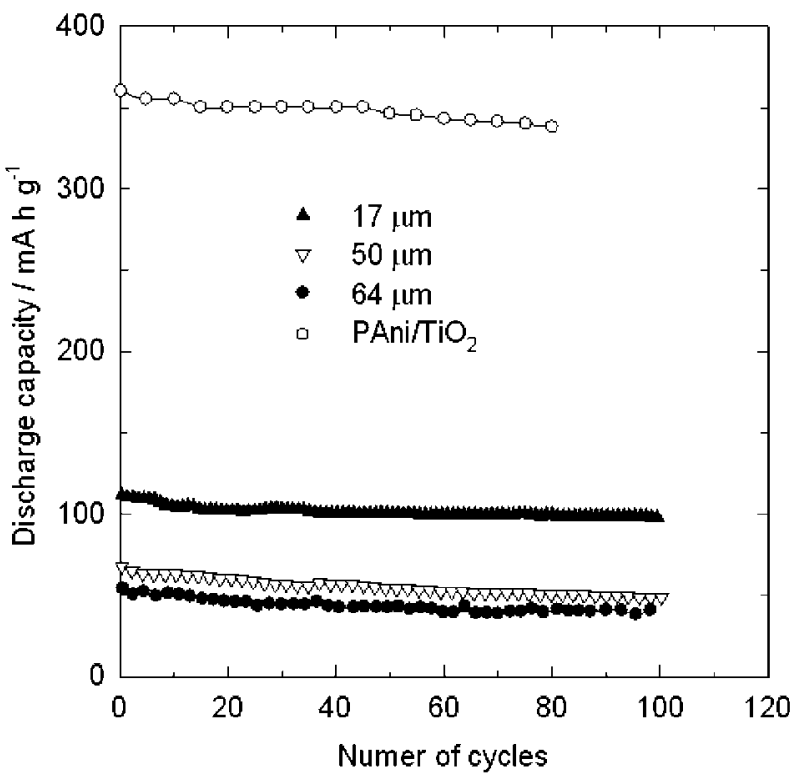

5 Comparison of discharge capacity between battery with polyaniline/ $/ \mathrm{TiO}_{2}$ composite cathode and zinc anode $^{17}$ and Li/PTMA battery with PTMA based cathodes of different thicknesses ${ }^{77}$

growth factor on its surface, linked with a layer of polyallylamine conjugated to an arylazido functional group. ${ }^{78}$ PPy was electrochemically synthesised to a $3 \mu \mathrm{m}$ thickness on a gold electrode. They found an increase of $50 \%$ in length in neurite growth under the influence of electrical stimulation. In another paper, Gomez et $a l .{ }^{79}$ reported that embryonic hippocampal neurons increase twofold the number of cells when cultured on electropolymerised PPy on ITO, patterned with 1 and $2 \mu \mathrm{m}$ wide channels using e beam lithography, in comparison with the neurons in non-patterned electropolymerised PPy. The roughness and morphology of the microchannels depended on the e beam current and polymerisation current, dopant concentrations and polymerisation time. In another study, the adhesion and proliferation of rat neuronal cells were compared on different electrodeposited polymers. Figure 6 presents the comparison of the different polymers and shows that PPy has limited growth cell than poly(ethyleneimine) (PEI), poly(propyleneimine) (PPI), fluorine doped tin oxide (FTO) and bare glass. ${ }^{80}$

Electrical stimulation through metal electrodes has been claimed to enhance bone healing, angiogenesis and growth of endothelial, nerve and bone cells. Further surgery, however, is necessary to remove the metal electrodes. This procedure can be avoided if a conductive biodegradable polymer can be used. Poly(pyrrole) (PPy), PAni and poly(acetylene) (PA) have been investigated as possible electrical conductors to replace the metal electrodes. A combination composite of a biodegradable polymer such as poly( $\varepsilon$-caprolactone) (PCL) with the mechanical strength and conductivity of PAni and a bioactive mesoporous silicon (BioSilicon) was tested by Whitehead et al., for orthopaedic potential applications. ${ }^{15}$ The authors showed that the calcification of the PCL/ PAni/biosilicon composite, increased under the application of electrical stimulation in simulated body fluid.

Richardson-Burns et al. ${ }^{81}$ studied central nervous system cells interacting with PEDOT to develop coatings for microelectrodes with potential applications in

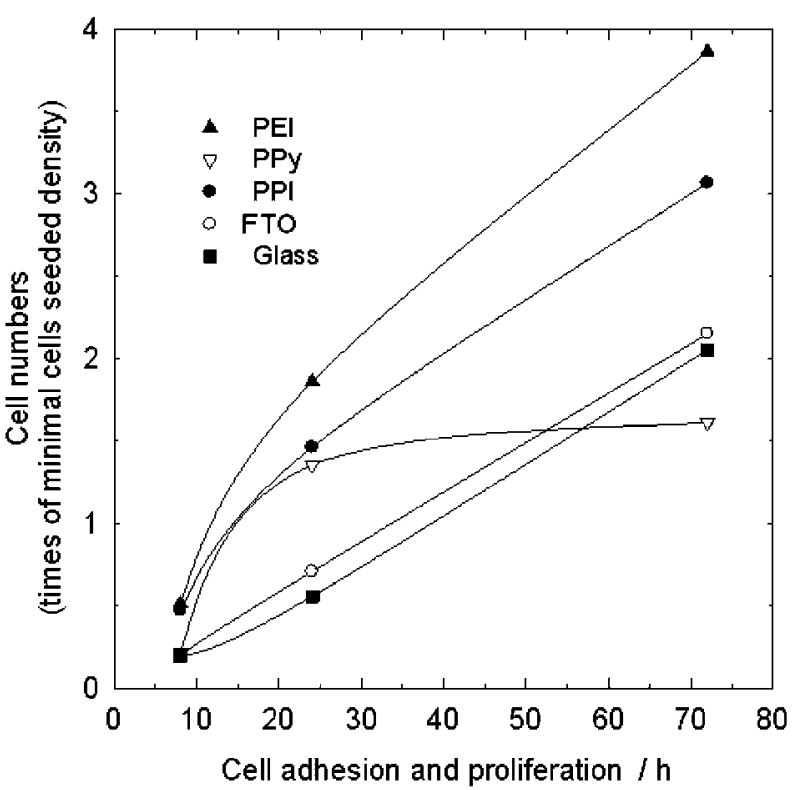

6 Comparison of neuronal cell adhesion and proliferation on different electrodeposited substrates including poly(ethyleneimine) (PEI), poly(pyrrole) (PPy), poly(propyleneimine) (PPI), fluorine doped tin oxide (FTO) and bare glass: each unit of minimal cell seeded density in vertical axis corresponds to 200000 cells $\mathrm{mL}^{-1}$ (Ref 80 )

therapies for neurological disorders such as chronic pain, Parkinson's disease or epilepsy. In a recent paper, the same authors electropolymerised PEDOT in the presence of living neural cells using $0 \cdot 5-1 \mu \mathrm{A} \mathrm{cm}^{-2}$ current density and found that the cells could be exposed to dopants such as ethylenedioxythiophene (EDOT) and PSS for $72 \mathrm{~h}$ maintaining $75 \%$ cell viability for $120 \mathrm{~h}$ after polymerisation. The polymerisation occurred around the cells and appeared to use the neural cells as scaffold for polymerisation, although not in areas where the cells were attached to the $\mathrm{Au} / \mathrm{Pd}(6 \mathrm{~mm}$ diameter) electrode. The authors observed by SEM that a PEDOT polymer covered delicate filopodia and neurite membranes might lead to a new generation of biosensors and 'smart' bioelectrodes.

\section{Conclusions}

1. Conducting polymers can combine the electronic characteristics of metals with the engineering properties of polymers.

2. Examples of conductive polymers which have been deposited and characterised, often using electrochemical techniques, include PPy, PTh and PAni.

3 . An increasing range of conductive polymer materials has been introduced over the last 30 years.

4. Application areas include electronic and optical materials, (bio)sensors, biomedical implants, actuators and corrosion protection together with energy storage and conversion.

5. In addition to single polymer coatings, specialised layers include composite and multilayer deposits consisting of conducting polymers containing a second phase of metal or ceramic which can be deposited.

6. The performance of modern conductive polymer coatings will be described in a further review in this series (Part 3). 


\section{References}

1. S. A. Campbell, Y. Li, S. Breakspear, F. C. Walsh and J. R. Smith: Trans. Inst. Met. Finish., 2007, 85, 237-244.

2. J. R. MacCallum and C. A. Vincent (eds.): 'Polymer electrolyte reviews'; 1987, Essex, Elsevier.

3. P. Chandrasekhar: 'Conducting polymers, fundamentals and applications: a practical approach'; 1999, Dordrecht, Kluwer Academic.

4. G. G. Wallace, G. M. Spinks, L. A. P. Kane-Maguire and P. R. Teasdale: 'Conductive electroactive polymers: intelligent materials systems', 2nd edn; 2002, Boca Raton, FL, CRC Press.

5. T. A. Skotheim, J. Reynolds and R. L. Elsenbaumer (eds.): 'Handbook of conductive polymers'; 1997, New York, Marcel Dekker.

6. R. B. Kaner: in 'Electrochemical science and technology of polymers', (ed. R. G. Linford), Vol. 2, 97; 1990, Essex, Elsevier Applied Science.

7. M. Satoh, K. Kaneto and K. Yoshino: J. Chem. Soc., Chem. Commun., 1985, 22, 1629-1630.

8. J. L. Bredás, R. R. Chance and R. Silbey: Phys. Rev. B, 1982, 26B, 5843-5854.

9. B. R. Weinberger, E. Ehrenfreund, A. J. Heeger and A. G. MacDiarmid: J. Chem. Phys., 1980, 72, 4749-4755.

10. C-C. Han and R. L. Elsenbaumer: Mol. Cryst. Liq. Cryst., 1990, 189, 183-192.

11. R. Baughman and L. W. Shacklette: in 'Science and applications of conducting polymers', (ed. W. R. Salaneck et al.), 47-61; 1990, Bristol, IOP Publishing.

12. P. M. George, A. W. Lyckman, D. A. LaVan, A. Hegde, Y. Leung and R. Avasare: Biomaterials, 2005, 26, 3511-3519.

13. M. Shahinpoor and K. J. Kim: Sens. Actuat. A, 2002, 96A, 125-132.

14. E. Armelin, R. Oliver, F. Liesa, J. I. Iribarren, F. Estrany and C. Alemán: Prog. Org. Coat., 2007, 59, 46-52.

15. M. A. Whitehead, D. Fan, G. R. Akkaraju, L. T. Canham and J. L. Coffer: J. Biomed. Mater. Res. A, 2007, 83A, 225-234.

16. S. Sathiyanarayanan, S. S. Azim and G. Venkatachari: Electrochim. Acta, 2007, 52, 2068-2074.

17. K. Gurunathan, D. P. Amalnerkar and D. C. Trivedi: Mater. Lett., 2003, 57, 1642-1648.

18. S. L. Johnson, H. K. Park and R. F. Haglund: Appl. Surf. Sci., 2007, 253, 6430-6434

19. A. Tiwari: J. Macromol. Sci. A, 2007, 44A, 735-745.

20. J. L. Lee, J. Y. Lee, J. H. Sung and H. J. Choi: Synth. Met., 2005, 152, 173-176.

21. J.-C. Xu, W-M. Liu and H.-L. Li: Mater. Sci. Eng. C, 2005, C25, $444-447$.

22. R. J. Waltman: Can. J. Chem., 1986, 64, 76-95.

23. A. O. Patil, Y. Ikenoue, F. Wudl and A. J. Heeger: J. Am. Chem. Soc., 1987, 109, 1858-1859.

24. N. C. Foulds and C. Lowe: Anal. Chem., 1988, 60, 2473-2478.

25. J. Hwang, D. B. Tanner, I. Schwendeman and J. R. Reynolds: Phys. Rev. B, 2003, 67B, 115205-115215.

26. G. Sonmez, P. Schottland and J. R. Reynolds: Synth. Met., 2005, 155, 130-137.

27. Y. Chang, K. Lee, R. Kiebooms, A. Aleshin and A. J. Heeger: Synth. Met., 1999, 105, 203-206.

28. H. Yashima, M. Kobayashi, K.-B. Lee, D. Chung, A. J. Heeger and F. Wudl: J. Electrochem. Soc., 1987, 134, 46-52.

29. P. Baüerle and K. U. Gaudl: Synth. Met., 1991, 43, 3037-3042.

30. R. Mirrazaei, D. Parker and H. S. Munro: Synth. Met., 1989, 30 265-269.

31. W. Büchner, R. Garreau, M. Lemaire and J. Roncali: J. Electroanal. Chem., 1990, 277, 355-358.

32. E. Håkansson, A. Amiet and A. Kaynaka: Synth. Met., 2006, 156 , 917-925.

33. K. K. S. Kumar, S. Geetha and D. C. Trivedi: Curr. Appl. Phys., 2005, 5, 603-608.

34. S.-M. Yuen, C.-C. M. Ma, C.-Y. Chuang, K.-C. Yu, S.-Y. Wu, C.-C. Yang and M.-H. Wei: Compos. Sci. Technol., 2007, to be published. DOI: 10.1016/j.compscitech.2007.08.004

35. W.-S. Jou and H.-Z. Cheng: J. Alloys Compd, 2007, 434 435, 641-645.

36. J. Roncali: Chem. Rev., 1992, 92, 711-738.

37. R. J. Waltman and J. Bargon: Tetrahedron, 1984, 40, 3963-3970.

38. D. J. Walton, J. Iniesta, M. Plattes, T. J. Mason, J. P. Lorimer, S. Ryley, S. S. Phull, A. Chyla, J. Heptinstall, T. Thiemann, H. Fuji, S. Mataka and Y. Tanaka: Ultrason. Sonochem., 2003, 10, 209-216.

39. S. Hotta, T. Hosaka and W. Shimotsuma: Synth. Met., 1983, 6, 319-320.
40. A. F. Diaz and J. Bargon: in 'Handbook of conducting polymers', (ed. T. J. Skotheim), Vol. 1, 81; 1986, New York, Marcel Dekker.

41. R. Jansson, M. Armin, R. Bjorklund and I. Lundstrom: Thin Solid Films, 1985, 125, 205-211.

42. A. R. Hillman and E. F. Mallen: J. Electroanal. Chem., 1987, 220, 351-367.

43. G. Dian, G. Barbey and B. Decroix: Synth. Met., 1986, 13, 281-289.

44. M. C. Lonergan, E. J. Severin, B. J. Doleman, S. A. Beaber, R. H. Grubbs and N. S. Lewis: Chem. Mater., 1996, 8, 2298-2312.

45. K. J. Albert, N. S. Lewis, C. L. Schauer, G. A. Sotzing, S. E. Stitzel, T. P. Vaid and D. R. Walt: Chem. Rev., 2000, 100, 25952626.

46. W. Zeng, M. Q. Zhang, M. Z. Rong and Q. Zheng: Sens. Actuat. B, 2007, 124B, 118-126.

47. A. Ramanavičius, A. Ramanavičienè and A. Malinauskas: Electrochim. Acta, 2006, 51, 6025-6037.

48. D. T. Glazhofer, J. Ulanski and G. Wegner: Polymer, 1987, 28, 449-453.

49. M.-A. Sato, S. Tanaka and K. Kaeriyama: J. Chem. Soc., Chem. Commun., 1985, 11, 713-714.

50. A. Czerwinski, H. Zimmer, C. V. Pham and H. B. Mark, Jr: J. Electrochem. Soc., 1985, 132, 2669-2672.

51. T.-C. Chung, J. H. Kaufman, A. J. Heeger and F. Wudl: Phys. Rev. $B, 1984$, 330B, 702-710.

52. O. Inganäs, B. Liedberg, W. Chang-Ru and H. Wynberg: Synth. Met. . 1985, 11, 239-249.

53. A. F. Diaz, J. Crowley, J. Bargon, G. P. Gardini and J. B Torrance: J. Electroanal. Chem., 1981, 121, 355-361.

54. M. Shahinpoor: Electrochim. Acta, 2003, 48, 2343-2353.

55. I. Jo: Surf. Eng., 2001, 17, 265.

56. U. Rammelt, P. T. Nguyen and W. Plieth: Electrochim. Acta, 2001, 46, 4251-4257.

57. $\bar{V}$ J. Gelling, M. M. Wiest, D. E. Tallman, G. P. Bierwagen and G. G. Wallace: Progr. Org. Coating, 2001, 43, 149-157.

58. W.-K. Lu, S. Basak and R. L. Elsenbaumer: in 'Handbook of conductive polymers', (eds. T. A. Skotheim et al.), 881-920; 1997, New York, Marcel Dekker.

59. Z. Deng, W. H. Smyryl and H. S. White: J. Electrochem. Soc., 1989, 136, 2152-2158.

60. D. W. DeBerry and A. Viehbeck: in 'The Electrochemical Society softbound proceedings series', 308-323; 1984, Pennington, NJ, Electrochemical Society.

61. S. Ren and D. Barkey: J. Electrochem. Soc., 1992, 139, 1021-1026.

62. D. E. Tallman, Y. Pae and G. P. Bierwagen: Corrosion, 2000, 56, $401-410$

63. B. Wessling: Synth. Met., 1997, 85, 1313-1318.

64. B. Wessling: Chem. Br., 2001, 37, 40-42.

65. S. M. Sayyah and M. M. El-Deeb: J. Appl. Polym. Sci., 2007, 103, 4047-4058.

66. L. Cecchetto, D. Delabouglise and J. P. Petita: Electrochim Acta, 2007, 52, 3485-3492.

67. J. R. Smith, P. A. Cox, N. M. Ratcliffe and S. A. Campbell: Trans. Inst. Met. Finish., 2002, 80, 1-4.

68. J. Bargon, S. Mohmand and R. J. Waltman: Mol. Cryst. Liq. Cryst., 1982, 93, 279-291.

69. A. R. Bishop, D. K. Campbell and K. Fesser: Mol. Cryst. Liq. Cryst., 1981, 77, 253-264.

70. G. P. Evans: 'Advances in electrochemical science and engineering', Vol. 1; 1990, Cambridge, Cambridge Life Science

71. J. L. Bredás and G. B. Street: Acc. Chem. Res., 1985, 18, 309-315.

72. R. Qian and J. Qiu: Polym. J., 1987, 19, 157-172.

73. G. Tourillon and F. Garnier: J. Electroanal. Chem., 1982, 135, 173-178.

74. Y. Ito, H. Shirakawa and S. Ikeda: J. Polym. Sci. A, 1996, 34A, 2533-2542.

75. P. Kovacic and A. Kyriakis, J. Am. Chem. Soc., 1963, 85, 454458.

76. E. M. Genies, G. Bidan and A. F. Diaz: J. Electroanal. Chem., 1983, 149, 101-113

77. J.-K, Kim, G. Cheruvally, J.-W. Choi, J.-H. Ahn, S. H. Lee, D. S. Choi and C. E. Song: Solid State Ionics, 2007, 178, 1546-1551.

78. N. Gomez and C. E. Schmidt: J. Biomed. Mater. Res. A., 2007, 81A, 135-149.

79. N. Gomez, J. Y. Lee, J. D. Nickels and C. E. Schmidt: Adv. Funct. Mater., 2007, 17, 1645-1653.

80. S. Lakard, G. Herlem, A. Propper, A. Kastner, G. Michel, N. Valles-Villareal, T. Gharbi and B. Fahys: Bioelectrochemistry, 2004, 62, 19-27.

81. S. M. Richardson-Burns, J. L. Hendricks, B. Foster, L. K Povlich, D-H. Kim and D. C. Martin: Biomaterials, 2007, 28, 1539-1552. 